\title{
Construction and evaluation of cultivated land ecological security system: a case study in Zhuhai city
}

\author{
Yinjie $\mathrm{HE}^{\mathrm{a}}$, Dafang $\mathrm{WU}^{\mathrm{b}}$, Yanyan $\mathrm{LIU}^{\mathrm{c}}$ and Jiaxin $\mathrm{WU}^{\mathrm{d}}$ \\ Institute of Land Resources and Urban-Rural Planning, College of Geographical Sciences, \\ Guangzhou University, Guangzhou 510006, China; \\ aAuthor email: Terrence17@163.com, ${ }^{\mathrm{b}}$ Corresponding author email: wudaf2004@163.com, \\ cemail: sunnylyy08@163.com, ${ }^{\mathrm{d}}$ email: 381629501@qq.com
}

\section{Keywords: Cultivated land; Ecological security; AHP; DPSIR model; Zhuhai}

Abstract. Research purposes: this paper concluded that cultivated land ecological security situation of Zhuhai, and forecast its future trend, to provide a scientific reference for Zhuhai cultivated land ecological security. Methods: through the Driver - Pressures - State - Impact - Responses(DPSIR model) combined with analytic hierarchy process (AHP) to build Zhuhai cultivated land ecological security system evaluation model, then using ArcGIS software to the spatial data processing and get the area of cultivated land ecological security level each year. Results show that: (1) Zhuhai for cultivated land ecological security in 1988: Level 2 accounted for $4 \%$ of the total area of cultivated land, and Level 3 accounted for $85.46 \%$ of the total area of cultivated land, and Level 4 accounts for $10.54 \%$ of the total area of cultivated land. (2) Zhuhai for cultivated land ecological security in 1998: Level 2 accounted for $7.41 \%$ of the total area of cultivated land, and Level 3 accounted for $47.17 \%$ of the total area of cultivated land, and Level 4 accounts for $45.37 \%$ of the total area of cultivated land, and Level 5 accounts for $0.05 \%$ of the total area of cultivated land. (3) Zhuhai for cultivated land ecological security in 2008: Level 2 accounted for $4.43 \%$ of the total area of cultivated land, and Level 3 accounted for $13.42 \%$ of the total area of cultivated land, and Level 4 accounts for $80.62 \%$ of the total area of cultivated land, and Level 5 accounts for $1.53 \%$ of the total area of cultivated land. Conclusion: Zhuhai increased cultivated land ecological security in 20 years, there is no level 1 of cultivated land. The cultivated land in 1988 was mainly 3 grade, and in 1998 was mainly 3 grade and 4 grade, in 2008 was mainly 4 grade.

\section{Introduction}

As is known to all, cultivated land with multi-functional. It can not only guarantee food security, provide industrial raw materials, at the same time, also has the function of ecological services and landscape. As China's industrialization and urbanization fast development, the ecological value of cultivated gradually manifest ${ }^{[1]}$. In recent years, the Chinese government has clearly put forward "the construction of ecological civilization in prominence", called for the Party and the national people's to build "Beautiful China". Should we found that the cultivated land ecological security research is a frontier of sustainable utilization of resources, explore the cultivated land ecological security is helpful to the construction of ecological civilization.

However, given China's national conditions, is currently in the primary stage of Socialism. As the population pressure, industry as well as the limitation of the thought idea, farmland from being destroyed by the man-made and natural. Most of China's arable land ecological safety is not optimistic. Therefore, to strengthen management by the relevant departments, it is necessary to build the safety status of cultivated land ecological security system analysis.

In fact, from the ecological perspective to analyze the function of the cultivated land has become a new hot spot of land science research at present in China ${ }^{[2-5]}$. But it is worth noting that, most of the studies of Chinese scholars are only to pay attention to some year of farmland ecological safety, the lack of a long span research ${ }^{[6]}$. Moreover, the municipal regional mesoscale is less, most is the study of the parcel or county scale. Considering the above analysis, this paper, taking the ecological point of view as the breakthrough point, explore the cultivated land ecological security of Zhuhai. Looking 
forward to providing the theory and decision-making basis for the Zhuhai cultivated land protection and sustainable development ${ }^{[7]}$.

\section{Methodology}

Analytic Hierarchy Process(AHP). The method is to decompose the elements related to into goals, rules, plans and so on level. Based on this to construct judgment matrix, calculate a level to other level a related index weight after normalization processing.

Cultivated land ecological security evaluation model.

1) According to the actual situation of Zhuhai, adjust measures to local conditions to select indicators, to build the city cultivated land ecological security evaluation index system (DPSIR). As shown in table 1:

Table 1 Zhuhai cultivated land ecological security evaluation model

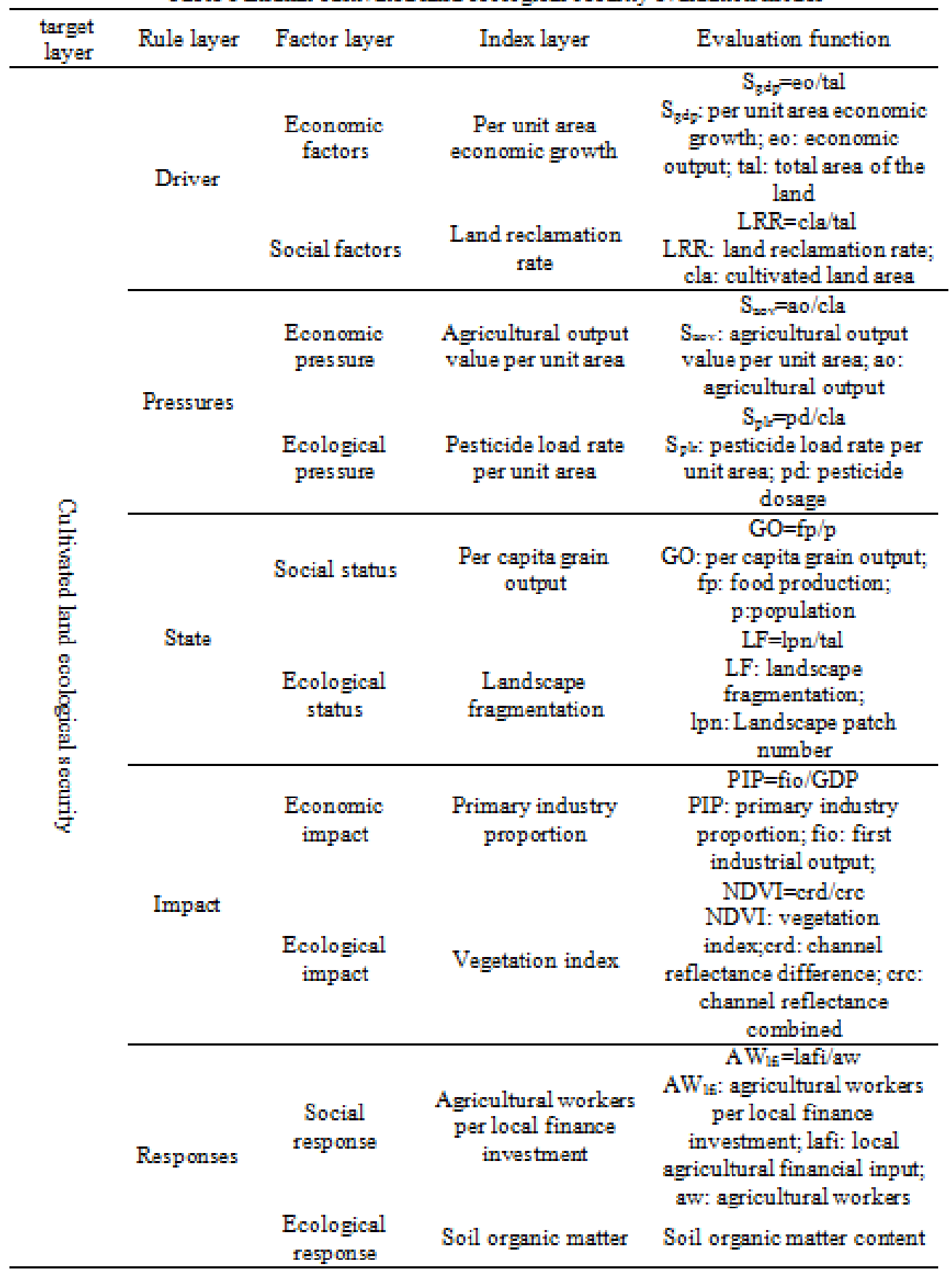


2) Construct one to one comparative judgment matrix of selected 10 indexes comparison. using numerical ${ }^{x_{a b}}$ to describe the $a$ element and the element $b$ relative importance to a layer of some factor. As shown in table 2:

Table 2 Comparative judgment matrix gradient

\begin{tabular}{cc}
\hline gradient & meaning \\
\hline 1 & The importance of $\mathrm{a}$ and $\mathrm{b}$ to a layer factor is the same $\mathrm{b}$ is somewhat important \\
5 & A is important than $\mathrm{b}$ \\
7 & A is more important than $\mathrm{b}$ \\
9 & A is extremely important than $\mathrm{b}$ \\
$2 、 6 、 8$ & The importance of a and $\mathrm{b}$ in between $x_{a b=2 \mathrm{n}-1 \text { and }} x_{a b=2 \mathrm{n}+1}$ \\
reciprocal & The ratio of the importance to $1 / x_{a b}$
\end{tabular}

3) Satisfied with the level of consistency check to, and then the index data normalization processing.

4) Ecological security index calculated on ArcGIS software, then using comprehensive weighted model formula $E_{i}=\sum_{1=1}^{10} \mathrm{PiCi}$. Finally to calculate cultivated land ecological security comprehensive value of Zhuhai.

\section{Data}

Data source. In this paper, the study area according to Landsat TM remote sensing images which including 1988, 1998, 2008 as data sources. Among them, the cultivated land area, land area, vegetation index and the number of landscape patches by remote sensing image interpretation; soil organic matter contents in 1988 and 1998 data are collecting the Second Soil Census results of China e.g. Zhuhai Soil, Doumen County Soil Census Report. The soil quality data in 2008 are alternative data, which using of Sun Yat-sen university in 2009 to field sampling soil samples for testing analysis. Other social and economic data, such as agricultural output, the output value of first industry, GDP, food production are taken from Guangdong Statistical Yearbook and Zhuhai Statistical Yearbook.

Data preprocessing. Standardization of data processing: calculation results is greater, and better for the cultivated land ecological security situation, with positive indicators calculated standardized treatment; the result is smaller, but better for the cultivated land ecological security situation, with a negative index for processing.

Positive index calculation formula:

$$
z_{i j}=\frac{x_{i j}-\min \left(x_{j}\right)}{\max \left(x_{j}\right)-\min \left(x_{j}\right)} .
$$

Negative index calculation formula: 


$$
Z_{i j}=\frac{\max \left(x_{j}\right)-x_{i j}}{\max \left(x_{j}\right)-\min \left(x_{j}\right)}
$$

Where $x_{i j}$ is the original value of index $\mathrm{j}$ in the year $\mathrm{i} ; Z_{i j}$ is the standardized value of index $\mathrm{j}$ in the year I; $\min \left(x_{j}\right)$ and $\max \left(x_{j}\right)$ is the minimum and maximum of index j.

\section{Results}

Result of AHP. Using special software Yaahp which is used to deal with analytic hierarchy (AHP), combined with judgment matrix, the related results are shown in table 3.

Table 3 the cultivated land ecological security evaluation index weight

\begin{tabular}{|c|c|c|c|c|c|c|c|c|c|c|}
\hline Index & $\begin{array}{l}\text { Per unit area } \\
\text { economic } \\
\text { growth }\end{array}$ & $\begin{array}{l}\text { Land } \\
\text { reclamation } \\
\text { rate }\end{array}$ & $\begin{array}{l}\text { Agricultural } \\
\text { output value } \\
\text { per unit area }\end{array}$ & $\begin{array}{c}\text { Pesticide } \\
\text { load rate per } \\
\text { unit area }\end{array}$ & $\begin{array}{l}\text { Per capita } \\
\text { grain output }\end{array}$ & $\begin{array}{c}\text { Landac-ape } \\
\text { fragmentation }\end{array}$ & $\begin{array}{l}\text { Primary } \\
\text { industry } \\
\text { proportion }\end{array}$ & NDVI & $\begin{array}{l}\text { Agricultural } \\
\text { workers per } \\
\text { local finance } \\
\text { invest-ment }\end{array}$ & $\begin{array}{l}\text { Soil organic } \\
\text { matter }\end{array}$ \\
\hline weight & 0.0723 & 0.2893 & 0.0648 & 0.1946 & 0.0465 & 0.1394 & 0.0148 & 0.0595 & 0.0396 & 0.0792 \\
\hline
\end{tabular}

Ecological safety threshold. Refer to Chinese and foreign related research ${ }^{[2,8-10]}$, and the calculation results. Based on the five level interval to define Zhuhai cultivated land ecological security evaluation. shown in table 4:

Table 4 Zhuhai cultivated land ecological security evaluation level

\begin{tabular}{cccccc}
\hline Normalized value & {$[0,0.15)$} & {$[0.15,0.40)$} & {$[0.40,0.60)$} & {$[0.60,0.85)$} & {$[0.85,1]$} \\
\hline Level & 1 & 2 & 3 & 4 & 5 \\
Ecological security & Unsafe & Relatively unsafe & Critical safe & Relatively safe & Safe \\
\hline
\end{tabular}

Level of Zhuhai cultivated land ecological security. According to the mentioned method in section 2, combined with Zhuhai cultivated land ecological security evaluation in table 4, it is concluded that the cultivated land ecology safe in 20 years. shown in table 5:

Table 5 Zhuhai area safety level unit:hm²

\begin{tabular}{cccccc}
\hline & & & & & \\
\hline \\
1988 & 0 & 2613.12 & 52995.51 & 6653.17 & 0 \\
1998 & 0 & 4022.78 & 25459.37 & 24489.46 & 52.20 \\
2008 & 0 & 1627.22 & 4923.42 & 29549.61 & 564.57 \\
\hline
\end{tabular}

Using ArcGIS software shows that the results of the section 4.3. shown in Fig. 1: 


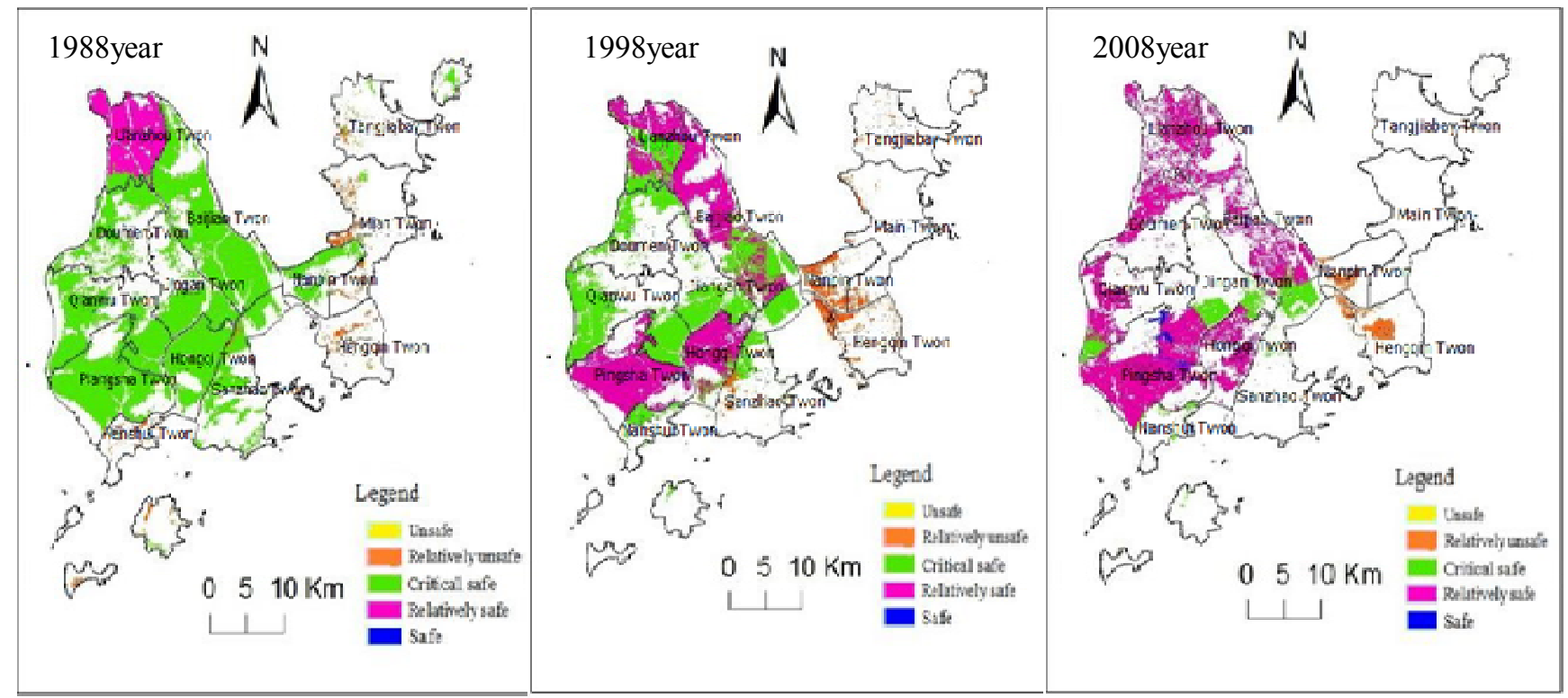

Fig. 1 1988, 1998, 2008 zhuhai cultivated land ecological security

Notes: (1) Yellow represents unsafe; (2) Orange represents relatively unsafe; (3) Green represents critical safe; (4) Magenta represents relatively safe; (5) Blue represents safe.

\section{Conclusions}

In this paper, we diagnosed cultivated land ecological security in Zhuhai based on the methodology presented in section 2 using ArcGIS. Main results are concluded below:

(1) The total area of cultivated land in reducing year by year from 1988 to 2008, But the cultivated land ecological security improved. There is no unsafe levels of cultivated land in Zhuhai. In 1988 focused on the relatively unsafe, the critical safety and relatively safe, which is given priority to with criticality safety; in 1998 also focused on the relatively unsafe, the critical safety and relatively safe, but relatively safe area increased significantly; in 2008 focused on the critical safe, the relatively safety and safe, relatively safe area continue to increase, appear level safe. It can be seen that cultivated land ecological security in Zhuhai rise year by year, the strong ability of sustainable development.

(2) Zhuhai should comply with the current "mountain, river, land, city, sea" the main body of the spatial pattern. The layout of the three large tracts which including Doumen district of northern, southern Baijiao town and Doumen district west along the border with Jinwan of cultivated land and basic farmland should be retained. Avoiding the ecological sensitive area, strengthening the quality of cultivated land, giving full play to the cultivated land ecological function. This way can add pastoralism and urban green open space, make the ecological construction and farmland protection organic unification for Zhuhai.

\section{Acknowledgements}

This work was financially supported by the National "Twelfth Five-Year" Plan for Science \& Technology Support(2013BAJ13B01), National Natural Science Foundation of China(41101078), Guangdong education department innovative projects(2014KTSCX090), Guangdong education scientific research "twelfth five-year" rules Row 2013 annual research project (2013JK134), Guangzhou "twelfth five-year" plan philosophy and social science(15Q28), the quality of undergraduate education and teaching reform project of guangdong province "Real estate management" high-quality goods resource sharing class, Guangzhou university demonstration experiment project 2015 "geographic information system application in land use planning" and College students' innovative training at the provincial level in guangdong province department of education Project (No.201611078085, CX2015025). 


\section{References}

[1] Song X Q, Huang Y, Wu Z F, et al., 2015. Does cultivated land function transition occur in China? Journal of Geographical Sciences, 25(7): 817-835.

[2] Li C Q, Lin S L, Liu J K, 2011. Analytic hierarchy process (AHP) application in Liaodong hilly land ecological security evaluation. Liaoning Agricultural Science, (3): 29-33. (in Chinese)

[3] Huang P, Lai X M, Huang L Y, 2012. Guangzhou dynamic cultivated land ecological security evaluation. Guangdong Agricultural Science, 12: 210-212. (in Chinese)

[4] Liu Y Y, Wu D F, Wang C H, 2011. Wetland ecological security evaluation is reviewed. Geography and Geographic Information Science, (01):69-75. (in Chinese)

[5] Guo X D, Qiu Y, Lian G, et al.,2008. Index System of Regional Land Quality and Application Research. Beijing: Science Press. (in Chinese)

[6] Tang X M, Pang Y C, Qin Y W, et al.,2013. The quality of cultivated land intensive agriculture evolution trend research: In Guangrao county of Shandong province as an example. Journal of natural resources, 28(2): 277-285. (in Chinese)

[7] Wu D F, Liu Y Y, Liu Y H, et al.,2015. The prospect of research cultivated land ecological security evaluation. Journal of Chinese Ecological Agriculture, (03):257-267. (in Chinese)

[8] Zuo W, Wang Q, Wang W et al., 2010. Regional ecological security evaluation index and standard research. China's Environmental Science, 30(1): 41-45. (in Chinese)

[9] Kris A. Johnson, Stephen Polasky, Erik Nelson, et al., 2012. Uncertainty in ecosystem services valuation and implications for assessing land use tradeoffs: an agricultural case study in the Minnesota River Basin. Ecological Economics, 79: 71-79.

[10] Xu H, Lei G P, Cui P D et al., 2011. Cultivated land ecological security assessment: Ningan of Heilongjiang province as example. Research of Soil and Water Conservation, 12(18): 180-189. (in Chinese) 